\title{
Evaluation of several lolitrem-free endophyte/perennial ryegrass combinations
}

\begin{abstract}
The fungal endophyte Acremonium Iolii, in association with its ryegrass host, produces both peramine, a feeding deterrent to Argentine stem weevil, and lolitrem $B$, a neurotoxin causing ryegrass staggers. Endophyte strains vary in the ratio of production of these alkaloids in the ryegrass. In field evaluations of several endophyte/ryegrass combinations, 'Endosafe', a zero lolitrem B, high peramine strain protectedits hostagainst Argentine stem weevil attack and did not cause ryegrass staggers in lambs grazing three of four ryegrass cultivars. Lambs on the endophyte-free and Endosafe combinations had the highest liveweight gains and while endophyte-free ryegrass did not cause ryegrass staggers it suffered significant stem weevil damage. Ryegrasses with their 'wild-type' endophyte and a high lolitrem B strain 'Waiau', had only minor stem weevil damage but caused severe ryegrass staggers and weight loss in lambs. Ryegrass with the no lolitrem $\mathrm{B}$, low peramine strain, '100A', suffered some stem weevil damage and although not causing ryegrass staggers, did cause weight loss in lambs. Ryegrass/endophyte metabolites in addition to lolitrem $\mathrm{B}$ may have affected animal performance on endophyte-infected ryegrass.
\end{abstract}

Keywords endophytc, Endosafe, perennial ryegrass,ryegrass staggers, Argentine stem weevil, liveweight gains, peramine, lolitrem B

\section{Introduction}

Resistance of perennial ryegrass (Lolium perenne L.) to Argentinestem weevil (Listronotus bonariensis Kuschel) attack and ryegrass staggers in grazing livestock are both associated with the endophyte Acremonium lolit (Latch, Christensen \& Samuels)(Prestidge et al. 1982; Fletcher \& Harvey 1981). The role of endophytes in pastoral agriculture in New Zealand has been reviewed recently by Fletcher et al.(1990).

The linking of one organism (in the same host) with two major problems in pastoral agriculture, and

\author{
L.R. FLETCHER', A.J. POPAY ${ }^{2}$ and B.A. TAPPER \\ 'DSIR Grasslands, Private Bag. Christchurch \\ ${ }^{2}$ DSIR Plant Protection, Private Bag, Palmerston North
}

the option of perennial ryegrass with or without endophyte, presented a dilemma for farmers in the drier regions. This option was available for any perennial ryegrass-based pasture, which comprise 75 $80 \%$ of New Zealand's arable pastures. The industry in general either opted for cultivars with endophyte for better persistence, and accepted the associated animal health problems, or turned to alternative perennial grass species (Fletcher et al. 1990). Although ryegrass staggers and stem weevil resistance are both associated with the same host/endophyte relationship, they are mediated by different toxins (Rowan \& Gaynor 1986; Gallagher et al. 1984). Peramine, the feeding deterrent to Argentine stem weevil, is a water-soluble pyrrolopyrazine alkaloid, which can be produced in culture (Rowan \& Gaynor 1986). Lolitrem B, the main neurotoxin implicated in ryegrass staggers, is a lipidsoluble indole diterpene (Gallagher et al. 1984). Lolitrem $B$ has so far been extracted only from ryegrass infected with A. lolii; it has not been produced by A.lolii in culture. This suggests the host ryegrass provides a precursor for, or at least plays a role in, metabolism of lolitrem B. Paxilline, a neurotoxin which produces symptoms similar toryegrass staggers, is produced by A. lolii in culture and has also been proposed as a precursor to lolitrem B (Gallagher et al. 1977; Weedon \& Mantle 1987).

Since the major endophyte effects (viz. ryegrass staggers and resistance to Argentine stem weevil attack) were mediated through two independent pathways the potential existed to exploit the benefits of endophyte by identifying or developing an endophyte which continued to produce peramine but produced zero or low levels of lolitrem B.

Such endophyte strains were isolated and introduced into several perennial ryegrasses using recently developed inocculation techniques (Latch \& Christensen 1985).

The A. lolii ryegrass association produces another mammalian toxin, the ergopeptine alkaloid ergovaline (Bacon et al. 1986; Rowan \& Shaw 1987; Rowanetal. 1990). This toxin has been implicated in the tall fescue toxicosis syndrome which occurs in cattle during summer in the US. The syndrome includes reduced liveweightgainsandlow serumprolactinlevels. These 
symptoms were also associated with the grazing of perennial ryegrass containing A. lolii (Fletcher \& Barrel1 1984). Since levels of ergovaline in ryegrass were similar to those recorded in the toxic tall fescue, the reduced prolactin levels, and possibly reduced liveweight gains found by Fletcher \& Barrell (1984) were probably linked to ergovaline in infected ryegrass.

This paperreports on the results from the first field evaluation of several "new" ryegrass endophyte combinations, including those producing low levels of lolitrem B.

\section{Materials and methods}

A strain of endophyte, 'Endosafe' was isolated from ryegrass and grown in culture. Endosafe produces zero or very low levels of lolitrem B and 'typical' levels of peramine in its host. Two other endophyte strains, '100A' and 'Waiau' (WA), were also isolated. $100 \mathrm{~A}$ produces zero or low levels of lolitrem B and low levels of peramine. WA, from a North Canterbury ryegrass ecotype, produces very high levels of both lolitrem B and peramine.

Using the technique developed by Latch \& Christensen (1985), Endosafe was inoculated into seedlings of four Grasslands perennial ryegrass cultivars: Pacific, Nui, Ruanui and Greenstone. WA was inoculated into all but Pacific; and 100A was inoculated into Greenstone and Ruanui only.

Seed from these plants was harvested in 1990 and sown into $126 \mathrm{~m} \mathrm{x} 7 \mathrm{~m}$ plots of cultivated, ryegrass-free Wakanui silt loam at Lincoln. Endophyte-free seed of all four cultivars, and seed of Pacific and Nui with their 'common' or 'wild type' endophyte, were sown as controls. These 15 unreplicated combinations or treatments were sown with $200 \mathrm{~kg} / \mathrm{ha}$ of DAP super-phosphate and without legume using a precision drill, at seeding rates of $3-10 \mathrm{~kg} / \mathrm{ha}$. Low seeding rates were necessitated by the limited availability of seed and to maximise the experimental area. A split application of urea (totalling $1.50 \mathrm{~kg}$ urea/ha) was made in spring.

The individually fenced plots were laxly grazed with hoggets for 14 days in spring to encourage the accumulation of basal plant tissue, increasing the potential for toxin production. With warm dry conditions the potential for ryegrass staggers and the expression of Argentine stem weevil damage was greatest for the summer/autumn grazing in Feburary, when the trial was conducted.

Five-month-old Coopworth and Romney lambs with known staggers susceptibility were grazed on luceme (non toxic) as one mob for 25 days until all were completely free of ryegrass staggers symptoms. Having had recent serious ryegrass staggers, the time required for toxins to reach threshold levels in the lambs was reduced and the potential for ryegrass staggers to occur on the trial (Fletcher 1983) was maximised.

The lambs were fasted for 24 hours, weighed, then allocated to treatments so that all 15 mobs had a similar mean weight per head, each mob had a similar quantity of herbage on offer per head and each mob had asimilarbalance of the two breeds. Lambs averaged 9 per treatment.

Conditions during the 6 weeks before grazing were warm and dry. However, at the start of grazing $50 \mathrm{~mm}$ of rain fell in 2 days, resulting in ryegrass growth rates of $50-60 \mathrm{~kg} / \mathrm{DM} / \mathrm{day}$. To cope with this increased growth and to reduce the time for grazing heights to reach the lower 'toxic zone', ewes were introduccd (in proportion to lamb numbers in each treatment) for $\mathbf{5}$ days. On all treatments grazing height was $30 \mathrm{~mm}$ or below for the last 7 days' grazing, maximising intake of toxic material.

Lambs were weighed 14 days after grazing began and again after 28 days when the trial concluded. Each weighing was preceded by a 24 -hour fast. Lambs were scored individually for incidence and severity of ryegrass staggers on 5 occasions during the trial using a modified Keogh scale (Keogh 1973).

The quantity of herbage present on each treatment before grazing and on 5 occasions during grazing was measured with a capacitance probe, calibrated against quadrats cut to ground level. Randomly selected herbage samples, cut at ground level, were taken from each treatment at the start, middle and at end of the trial. These were then freeze dried and analysed for lolitrem B, ergovaline and peramine content (Rowan \& Shaw 1987; Tapperet al. 1989). Fresh samples were taken at the start of the trial; stained epidermal strips from leaf sheaths were examined under a light microscope (Latch \& Christensen 1985) to determine the percentage of tillers with endophyte.

Argentine stem weevil numbers (adults and larvae) were assessed for each treatment in September and December. Larval numbers were assessed from randomly selected tillers in Decemberusing themethod of Goldson (1978). Adult and larval damage was scored in March on 100 tillers randomly selected from each treatment. Larval damage were recorded as light, moderate or severe.

Although the trial was neither balanced nor fully replicated, the effect of endophyte strain and ryegrass cultivar were tested statistically using the interaction as an error term.

\section{Results}

In Greenstone WA and 100A treatments, 60 and $80 \%$ respectively of tillers were infected with endophyte. Apart from endophyte-free treatments, which had no 
endophyte. all other treatments had more than $95 \%$ of tillers infected with endophyte.

Endophyte strain had a significant effect on ryegrass staggers $(\mathrm{P}<0.01)$ at all observations (Figure 1). Lambs on WA and wild-type treatments were more affected than those on 100A, Endosafe and endophyte-free. Lambs on the Ruanui/Endosafe treatment showed mild ryegrass staggers despite the absence of lolitrem $B$.

Endophyte strain significantly affected liveweight gain over the total trial period $(\mathrm{P}<0.01)$ (Figure 2). where on average lambs on endophyte-free and Endosafe treatments gained weight while those on other treatments lost weight. Lambs on 100A, Endosafe and common endophyte treatments did not differ significantly for the first 14 days. These treatments gained less weight than endophyte-free treatments but more than for WA.

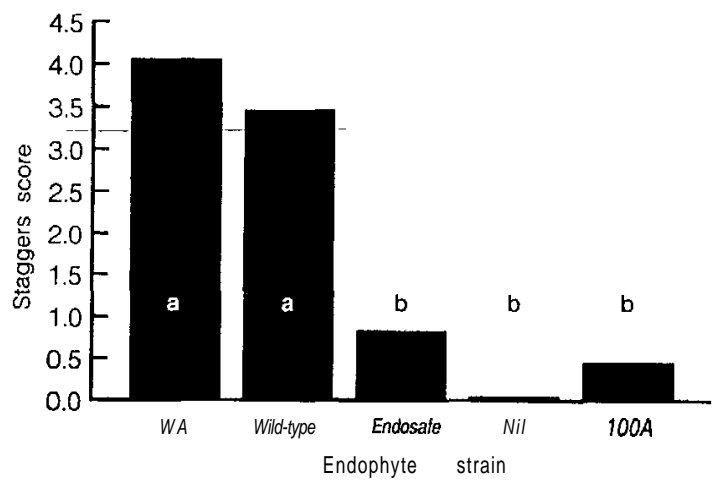

F igure 1 Ryegrass staggers scores during Februrary-March for lambs grazing perennial ryegrass with different endophytetreatments. (M eans of 5 scores over 28 days). Treatments with the same letters an not significantly different.

During the second 14 days herbage availability limited liveweight gain tovarious degrees,particularly on some endophyte-free treatments, as a result of the higher palatability of these treatments and consequent higher intake during the first period. All animals lost weight during the second 14-day period as herbage availability decreased.

The presence of endophyte significantly reduced Argentine stem weevil damage. The percentage of tillers with adult feeding was significantly higher in the nil endophyte treatment than in the endophyteinfected treatments in March (Figure 3.). Number of tillers damaged by adult feeding did not differ significantly in the wild-type and $100 \mathrm{~A}$ treatments. Larval densities recorded in December were approximately 1.8 times higher on the nil endophyte treatments than on Endosafe, WA or wild-type treatments, with numbers on 100A intermediate between these groups. Tiller damage by larvae followed a similar pattern, with a mean of $8.5 \%$ of tillers from

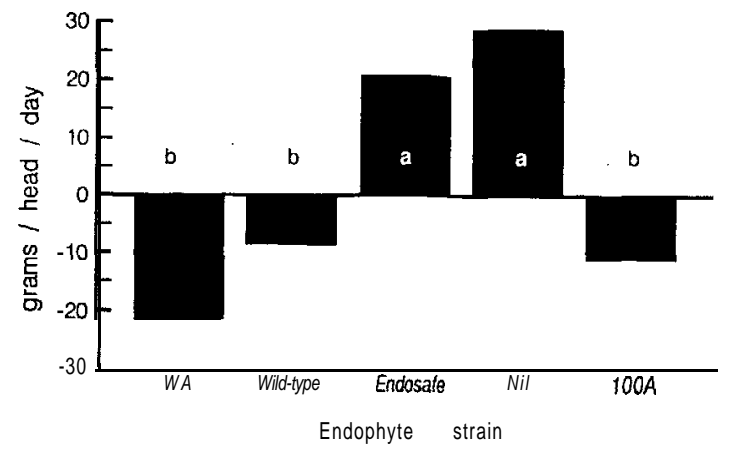

Figure $2 \mathrm{M}$ ean liveweight change in lambs grazing perennial ryegrass with different endophyte treatments. Treatments with the same letters are not significantly different.

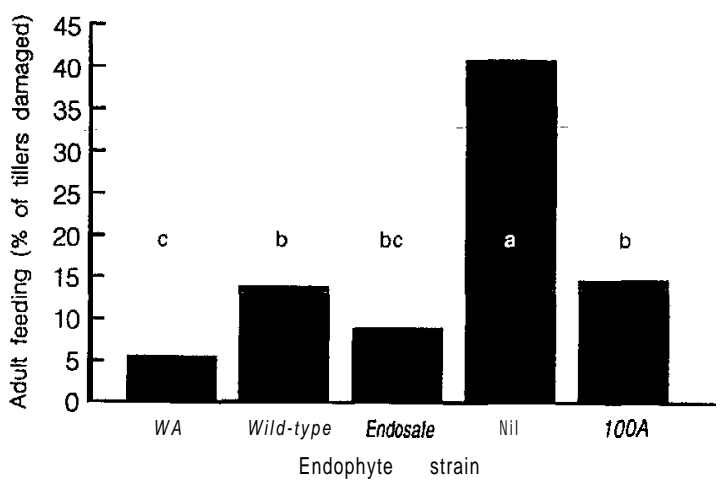

Figure 3 Perennial ryegrasstillers (as $5 \%$ of total tillers) damaged by Argentine stem weevil adults on perennial ryegrass with different endophyte treatments. Treatments with the same letters are not significantly different.

theendophyte-freeplotsdamagedcompared with $3.6 \%$ from the infected plots. Tiller damage was much less severe when endophyte was present. A cultivar effect was also apparent, with Greenstone showing more adult and larval attack than other cultivars.

Mean peramine and lolitrem $B$ concentrations, in field samples collected on 5 occasions throughout the trial (Table 1) were similar to those in the original ryegras plants innoculated with endophyte. They were alsoconsistent with the patterns of stem weevildamage and ryegrass staggers (Figures 1 and 3 ).

Table 1 Effect of endophyte strain on peramine and lolitrem $B$ concentrations (ppm), means from five sample dates.

\begin{tabular}{lcc}
\hline & Peramine & Lolitrem B \\
\hline W A & 17.7 & 8.0 \\
Wild-type & 10.5 & 4.7 \\
Endosafe & 11.3 & 0.1 \\
100A & 4.2 & 0 \\
Endophyte-free & 0.1 & 0 \\
\hline
\end{tabular}




\section{Discussion}

All cultivars with Endosafe showed good resistance to Argentine stem weevil compared with wild-type and endophyte-free combinations, and three of the four Endosafe combinations did not cause any significant ryegrass staggers in grazing lambs in summer. This is a significant finding for the pastoral industry, but mild staggers in lambs grazing Ruanui with Endosafe suggests caution may be needed in extrapolating these results to other ryegrass cultivars inoculated with Endosafe. Lambs grazing Ruanui with WA had more severe staggers than other cultivars with the same endophyte. Significant effects of host cultivar on the development of ryegrass staggers have recently been demonstrated (Fletcher \& Sutherland unpubl.). As lolitrem B cannot be produced from 'normal' endophyte culture, only by the endophyte in conjunction with its host, the host ryegrass may produce a precursor to lolitrem B. These indications of possible interaction between cultivar, or host plant genotype, and endophyte must be further investigated.

Regression of lolitrem B concentrations against ryegrass staggers using data from all treatments established that lolitrem B concentration is closely correlated with ryegrass staggers $(r=0.92)$ However, Ruanui with Endosafe had zero lolitrem B at all samplings yet caused mild, but significant, ryegrass staggers. This suggests other tremorgens may be involved, e.g. paxilline (Gallagher et al. 1977; Weedon \& Mantle 1987; Gallagher \& Prestidge 1990).

Our results agree with previously published reports on the effect of wild-type endophyte and endophytefree ryegrass on liveweight (Fletcher et al. 1990). The weight loss in lambs on the lolitrem B-free 100A treatments suggests toxins, present in endophyteinfected ryegrass, in addition to lolitrem B, may influenceliveweight change, e.g. ergopeptine alkaloids (Fletcher \& Barrel1 1984; Bacon et al. 1986; Rowan et al. 1990; Piper \& Fletcher 1990).

The Waiau, common and Endosafe endophytes all conferred a high degree of resistance to stem weevil. Plants with the $100 \mathrm{~A}$ strain also showed good resistance despite lower concentrations of the feeding deterrent peramine (Table 1). Levels of larval damage in March were relatively low, but damage would probably have been considerably higher during summer.

Although Endosafe has successfully demonstrated that the benefits of endophytes can be exploited while overcoming animal health problems, future research needs to evaluate the role of known, and any as yet unidentified, plant/endophyte metabolites and examine the role of the host plant in toxin production and manifestation of effects on animal health and performance.

\section{ACKNOWLEDGEMENTS}

Drs G. Latch and D. Rowan and the team from DSIR Plant protection identified and isolated the endophytes used in this study and inoculated thevarious ryegrasses with them. Without their skill and dedication Endosafe could not have been successfully developed. Drs S. Easton and P. Rolston for multiplication of seed. J. Hoglund and Dr J. Rowarth for assistance with statistical analysis and preparation of this paper. B. Sutherland, I.Baird and Mrs C. Fletcher for technical assistance and Mr P. Clifford and Dr J. Hay for support and encouragement. Dr J. A. K. Farrell and M. W. Stufkens for December sampling of Argentine stem weevil.

\section{REFERENCES}

Bacon, C.W.; Lyons, P.C.: Porter, J.K.; Robbins, J.D. 1986. Ergot toxicity from endophyte-infected grasses: A review. Agronomy journal 78: 106-116.

Fletcher, L.R. 1983. Effects of presence of Lolium endophyte on growth rates of weaned lambs, growing on to hoggets, on various ryegrasses. Proceedings of the NZ Grassland Association 44: 237-239.

Fletcher,L.R.;Barrell,G.K. 1984. Reducedliveweight gains and serum prolactin levels in hoggets grazing ryegrasses containing Lolium endophyte. NZ Veterinary Journal 32: 139-140.

Fletcher, L.R.; Harvey, I.C. 1981 An association of a Lolium endophyte with ryegrass staggers. NZ Veterinary Journal 29: 185-186.

Fletcher L.R.; Hoglund J.H.; Sutherland B.L. 1990. The impact of Acremonium endophytes in New Zealand, past, present and future. Proceedings of the NZ Grassland Association 52: 227-235.

Gallagher, R.T.; Hawkes, A.G.; Steyn, P.S.; Vleggaar, R. 1984. Tremorgenic neurotoxins from perennial ryegrass causing ryegrass staggers disorder of livestock: structure and elucidation of lolitrem B. Journal of the Chemical Society, chemical communications (London): 614-616.

Gallagher, R.T.; Keogh, R.G.; Latch,G.M.C.; Reid, C.S.M. 1977. The role of fungal tremorgens in ryegrass staggers. New Zealand Journal of Agricultural research 20: 431-430.

Gallagher, R.T.; Prestidge, R.A. 1990. Structureactivity studies on indole diterpenes, including lolitrems and related indoles and tremorgens. Proceedings of the 1st International Symposium on Acremonium/Grass Interactions. pp 80-8 1.

Goldson S.L. 1978. Simple technique for extracting Argentine stem weevil (Hyperodes bonariensis) larvae from ryegrass tillers (Coleoptera: Curculionidae) The New Zealand Entomologist 6:437. Keogh, R.G. 1973. Induction andprevention 
of ryegrass staggers in grazing sheep. NZ Journal of Experimental Agriculture I: 55-57.

Latch, G.C.M.; Christensen, M.J. 1985. Artificial infection of grasses with endophytes. Annals of Applied Biology 107: 17-24.

Piper, E.L.; Fletcher, L.R. 1990. Influence of adopamine antagonist on ryegrass staggers. Proceedings of the 1 st International Symposium onAcremonium/Grass Interactions. pp 248-249.

Prestidge,R.A.; Pottinger, R.P.; Barker, G.M. 1982. An association of Lolium endophyte with ryegrass resistance to Argentine stem weevil. Proceedingsof the 35th NZ Weed and Pest Control Conference: $119-122$

Rowan, D.D.; Gaynor, D.L. 1986. Isolation of feeding deterents against Argentine stem weevil from ryegrass infected with Acremonium lolii.Journal of Chemical Ecology 12: 647-658.
Rowan,D.D.; Shaw,G.J. 1987. Detectionofergopeptine alkaloids in endophyte-infected perennial ryegrass by tandemmass spectrometry. NZ Veterinary Journal 3.5: $197-198$

Rowan D.D.; Tapper B.A.;, Sergejew N.L.; Latch G.C.M. 1990. Ergopeptide alkaloids in endophyte-infected ryegrasses and fescues in New Zealand. Proceedings of the I st International Symposium on Acremoniuml Grass Interactions. pp 97-99.

TapperB.A.; RowanD.D.;LatchG.C.M. 1989. Detection and measurement of the alkaloid peramine in endophyte-infected grasses. Journal of Chromotography 463: 133-138.

Weedon, CM.; Mantle, P.G. 1987. Paxilline biosynthesis by Acremonium loliae; a step towards defining the origin of lolitrem neurotoxins. Phytochemistry 26: 969-971. 